\title{
Investigation into the Cytoprotective Potential of Ethanol Extract of DenettiaTripetalain Wistar Rat
}

\author{
Mfem CC ${ }^{1}$, Seriki SA ${ }^{2 *}$, Ewona $\mathrm{B}^{3}$ and Okeke JC ${ }^{4}$ \\ ${ }^{1}$ Department of Physiology, University of Calabar, Calabar, Nigeria \\ ${ }^{2}$ Department of Physiology, Edo University, Iyamho, Nigeria \\ ${ }^{3}$ Department of General Studies, College of Health Technology, Calabar, Nigeria \\ ${ }^{4}$ Department of Physiology, Chukwuemeka Odimegwu Ojukwu University, Uli, Nigeria \\ *Corresponding author: Seriki SA, Department of Physiology, College of Medical Sciences, Edo University, Iyamho, Nigeria. \\ To Cite This Article: Mfem CC, Seriki SA, Ewona B, Okeke JC. Investigation into the Cytoprotective Potential of Ethanol Extract of \\ DenettiaTripetalain Wistar Rat. 2020 - 9(2). AJBSR.MS.ID.001371. DOI: 10.34297/AJBSR.2020.09.001371.
}

Received: 眥 June 04, 2020; Published: 䟧 June 16, 2020

\begin{abstract}
Pepper fruit (Dennettia tripetala) is well known for its wide range of medicinal values which include bowel cleansing, facilitation of digestion and absorption of cholesterol, anti-cancerous effect, anti-microbial effect among many others. But not much has been reported on its cytoprotective effect on the gastric mucosa in spite its widespread use. The current study therefore focuses on evaluating the cytoprotective effect of the extract in wistar rats. Fifteen (15) rats weighing 160-180g were randomly assigned into three groups of five rats each. Group 1 (control), group 2 (low dose group) and group 3(high dose group). Group 1 received $0.5 \mathrm{ml}$ of normal saline while Groups 2 and group 3 (experimental groups) received respective doses of $0.00085 \mathrm{ml} / \mathrm{g}$ body weight and $0.0017 \mathrm{ml} / \mathrm{g}$ body weight of the extract. The administration was twice a day and lasted for 28 days. All the animals were allowed free access to normal rat chow and water. At the end of the experimental days, the animals were weighed after they were starved overnight. They were anaesthetized with $25 \%$ urethane $(0.6 \mathrm{ml} / 100 \mathrm{~g}$ body weight). Laparotomy was performed and the stomach isolated and cut open along the greater curvature, rinsed with normal saline and fastened in place with pins on a dissecting board for ulcer examination and score. The results obtained showed mean ulcer score of $8.5 \pm 0.5 \mathrm{mMol} / \mathrm{l} / \mathrm{hr}, 14.75 \pm 0.48 \mathrm{mMol} / \mathrm{l} / \mathrm{hr}$ and $20.5 \pm 0.96 \mathrm{mMol} / \mathrm{l} / \mathrm{hr}$ for control, group 2 and group 3 respectively. This increase is statistically significant $(\mathrm{p}<0.001)$ compared to control. Pepper fruit (Dennettiatripetala) is a poor cytoprotective agent and has shown a dose-dependent poor cytoprotective influence on the gastric mucosa
\end{abstract}

Keywords: Cytoprotection; Gastric Mucosa; Denettiatripetala; Wistar Rats

\section{Introduction}

Pepper fruit (Denettiatripetala) is widely cultivated in the rain forest zones of Nigeria and sometimes in the Savanna. It is reputed for bowel cleansing, facilitation of digestion and absorption of cholesterol, anti-cancerous effect, anti-microbial effect. It is also often used to spice food and to remedy cough, fever, toothache, diabetes and nausea. The barks of pepper fruits can be mixed with foods to create variations in taste and flavor. It is a $\mathrm{H} 2$ receptor agonist and increase gastric secretion at all quantities [1].

The young leaves (tiny and spear shape) and fruits of Denettiatripetala have a distinctive spicy taste. The spear shape fruits houses 2 to 3 seeds with pungent sensations. In most parts of Nigeria, the entire plant products of Denettiatripetalais used to serve useful medicinal and nutritional values. The fruits are sometimes taken with cola nuts, garden eggs and palm wine in Southern Nigeria, es pecially during festivals. Denettiatripetala fruits can also be used to season meat, so usage, stew, soup and vegetables. Meals spiced with Denettiatripetala are locally recommended for pregnant and lactating mothers in Nigeria for the claim that the herbs aides uterine contraction during delivery and enhances lactation [2].

\section{Classification}

Below is the classification of Denettiatripetala

$\begin{array}{lll}\text { Kingdom } & - & \text { Plantae } \\ \text { phylum } & - & \text { Magnoliophyta } \\ \text { Class } & - & \text { Magnoliopsida } \\ \text { Order } & - & \text { Magnoliales } \\ \text { Family } & - & \text { Annonaceae } \\ \text { Genus } & - & \text { Dennettia }\end{array}$




$\begin{array}{lll}\text { Species } & \text { Tripetala } \\ \text { Binomial name - } & \text { Dennettiatripetala } \\ \text { Synonyms - } & \text { Uvariopsistripetala [2]. }\end{array}$

\section{Chemical Composition of Denettiatripetala}

Proximate composition, calorific value and hydrogen cyanide content of Dennattiatripetala

$\begin{array}{lll}\text { Crude Protein } & - & 15.31 \% \\ \text { Fat oil } & - & 3.47 \% \\ \text { Carbohydrate } & - & 62.00 \% \\ \text { Ash } & - & 4.25 \% \\ \text { Crude fibre } & - & 9.84 \% \\ \text { Moisture } & - & 8.00 \% \\ \text { Calorific value } & - & 480.24 \mathrm{gCal}^{-1} 100 \mathrm{~g}- \\ \text { Dry matter } & - & 92.00 \mathrm{~g} 100 \mathrm{~g}^{-} \\ \text {Hydrogen cynade } & - & 0.02 \mathrm{mg}^{-} \mathrm{kg}^{-1}[3] .\end{array}$

\section{Mineral composition of Dennettiatripetala}

$\begin{array}{lcc}\text { Calcium } & - & 1.80 \% \\ \text { Magnesium } & - & 0.42 \% \\ \text { Phosphorus } & - & 0.33 \% \\ \text { Sodium } & - & 0.72 \% \\ \text { Potassium } & - & 2.50 \% \\ \text { Iron } & - & 17.75 \% \\ \text { Copper } & - & 0.78 \% \\ \text { Zinc } & - & 2.30 \% \\ \text { Cadimium } & - & 0.29 \mathrm{mg} \cdot \mathrm{Kg}^{-1} \\ \text { Manganese } & - & 2.01 \mathrm{mg} \cdot \mathrm{Kg}^{-1} \mathrm{Cobalt} \\ & - & 0.55 \mathrm{mg} \cdot \mathrm{Kg}^{-1}\end{array}$

[3].

\section{Water Soluble Vitamins}

$\begin{array}{ll}\text { Ascorbic acid (Vitamin C) } & 58.48 \mathrm{mg} \cdot 100^{-1} \\ \text { Riboflavin (Vitamin B2) } & 0.56 \mathrm{mg} \cdot 100^{-1} \\ \text { Thiamine (Vitamin B1) } & 012 \mathrm{mg} \cdot 100-^{-1} \\ \text { Niacin (nicotinic acid) } & 10.08 \mathrm{mg} \cdot 100^{-1} \text { [3]. }\end{array}$

Phytochemical constituents of the seeds of $D$. tripetala fruits on dry weight basis

Flavonoids

$2.26 \mathrm{mg} / 100 \mathrm{~g}$

$\begin{array}{llll}\text { Saponins } & - & 1.44 \mathrm{mg} / 100 \mathrm{~g} \\ \text { Alkanoids } & - & 0.24 \mathrm{mg} / 100 \mathrm{~g} \\ \text { Tannins } & - & 0.06 \mathrm{mg} / 100 \mathrm{~g} & \\ & & 0.03 \mathrm{mg} / 100 \mathrm{~g} \quad[3] .\end{array}$

\section{Cytoprotection}

Cytoprotection means protection against mucosa injury by mechanisms order than inhibition or neutralization of gastric acid. Several mechanisms of gastric cytoprotection has been proposed like increased mucus and bicarbonate secretion, strengthening of gastric mucosa barrier, increased gastric mucosa blood flow, decreased gastric motility, increased formation of prostaglandins and sulfyldryls scavenging of free radicals, stimulation of cellular growth and repair, decreased release of leukotrions etc. [4] Some cytoprotective drugs used as therapy for peptic ulcer include, sucralfate, colloidal bismuth and aluminum containing antacids. Peptic ulcer is a lesion of the alimentary mucosa which results in superficial loss of the tissue caused by digestive action of the gastric juice. Characteristically, it occurs in one of the following six sites in descending order of frequency [5].

a) The duodenum

b) The stomach

c) The oesophagus

d) The margin of the stroma of a gastroenterostomy

e) The Menkel's diverticulum with heterotopic gastric mucosa

f) The gastro jejunum.

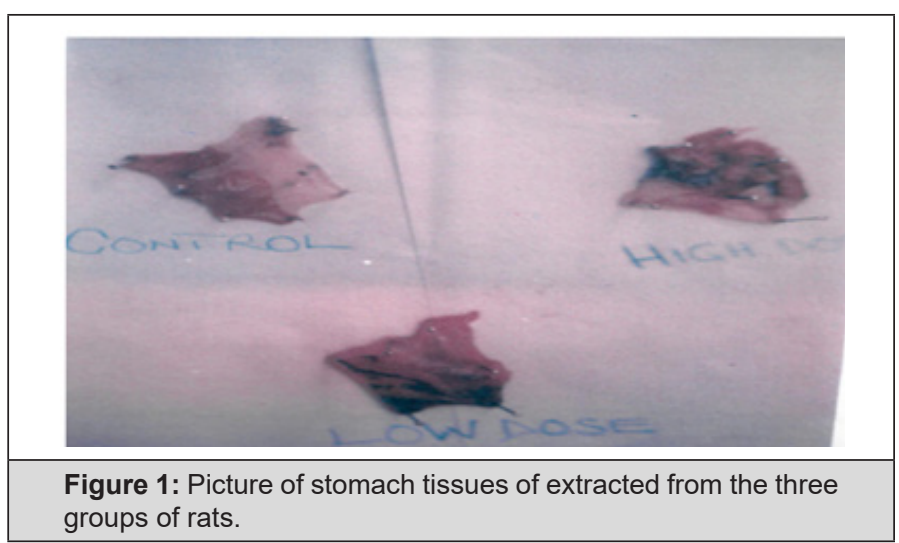

In the last two decades, considerable research has been carried out in order to gain an insight into the pathogenesis of peptic ulcer. Two basis features common to all peptic ulcers include (a) they occur only in the gastrointestinal tract in the mucosa exposed to acid peptic secretion (b) Peptic ulcer is focal lesions usually occurring singly. These are explained on the basis that ulcers result from imbalance between the aggressive actions of acid peptic secretion 
and the resistance of the gastroduodenal mucosa to acid proteolytic digestion. Hence, increased level of gastric acidity is requisite. Therefore it is said that "no acid, no ulcer".

\section{Materials and Methods}

\section{Experimental Animals}

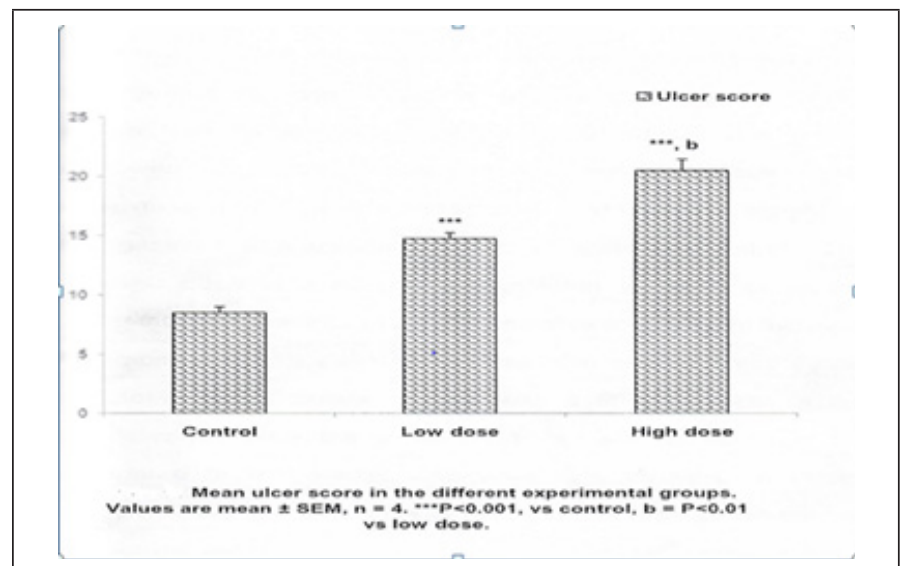

Figure 2: Histogram representation of mean ulcer score in the three groups of animals.

A total of fifteen male Wister rats weighing 160-180g were used for this experiment. The rats were purchased from the central Animal House of the Department of Physiology, Faculty of Basic Medical Sciences, University of Calabar, Cross River State, Nigeria, West Africa. The rats were kept in iron cages under standard laboratory conditions at room temperature with $12 \mathrm{~h}$ light/dark cycle with access to standard laboratory diet and water ad libitum.

\section{Experimental Plant}

Fresh mature fruits of Dennettiatripetala were purchased from the nearby bush market in Calabar, Nigeria and were authenticated by the chief botanist of the Department of Biological Science, University of Calabar, Calabar, Nigeria, West Africa, where voucher specimens were deposited in their herbarium.

\section{Drugs and Chemicals}

Urethane, $1.5 \mathrm{ml}$ acid alcohol, $0.1 \mathrm{~N} \mathrm{NaOH}$, ethanol

\section{Extraction and isolation}

Ripe fruits of Dennettiatripetala were obtained from the bush, washed to be free from debris and sundried for two days and later dried with AstellHearson oven at a temperature range 450C - 500C. The dried sample was milled with an electric blender and finally pulverized into powder with a manual blender. $200 \mathrm{~g}$ of the powder sample was extracted with $95 \%$ ethanol $(500 \mathrm{ml})$ in a soxhlet for $24 \mathrm{hrs}$. The ethanol extract was concentrated using a rotator evaporator at 450C and hot air circulating oven to obtain dark brown oil (15g; 7.5\% yield). The oil was left overnight at laboratory temperature for complete evaporation of remaining ethanol. The extract was stored in dark air tight bottles and refrigerated at $40 \mathrm{C}$ temperature for usage.

\section{Experimental Protocol and Administration of Extract}

Fifteen wistar rats were randomly assigned into three groups of five rats each, Thus; Groups A (Control group), group B (Low dose group) and group C (High dose group). 1g of DT extract was dissolved in $10 \mathrm{ml}$ distilled water and administration was done orally according to weight. The experimental groups ( $\mathrm{B}$ and $\mathrm{C}$ ) took $0.00085 \mathrm{ml}$ and $0.0017 \mathrm{ml}$ of extract respectively whereas the control group received $0.5 \mathrm{ml}$ of distilled water everyday.

\section{Preparation of Animals for Collection of Gastric Acid}

The animals were kept in cages in a well-ventilated room and fed with normal rat pellets. Water was also given ad libitum. The cages were sansitized daily; food and water were also changed regularly.

\section{The Experiment (Cytoprotection Study)}

The cytoprotection experiment was done [6]. After 28 days, the animals were weighed after being starved overnight. They were anaesthetized with $25 \%$ urethane $(0.6 \mathrm{ml} / 100 \mathrm{~g}$ body weight). $2 \mathrm{ml}$ of crude dennettia extract was instilled into the stomach via a portex cannula tied and left in place following an incision made on the antral-pyloric junction of the stomach. This was left to stand for one hour (1hr) and flushed with normal saline. The stomach was then instilled with $2 \mathrm{ml}$ of acid-alcohol ( $1 \mathrm{ml}$ of $\mathrm{HCl}, 1 \mathrm{ml}$ of $70 \%$ alcohol) and ligated as before. This stood for $1 \mathrm{hrs}$ after which the stomach was flushed again. After 1hr, laparotomy was performed and the stomach isolated and opened along the greater curvature, rinsed with normal saline and fastened in place with pins on a dissecting board and examined for ulcer scores with the magnifying lens. The ulcer score was then carried out after the method described by Ibu et al modified by Ohara.

\section{Determination OF Ulcer Score}

The ulcer scoring was done as follows;

Grade:

$0=\quad$ No lesions

$1=$ Haemorrhagic erosion (less than $5 \mathrm{~mm}$ )

$2=$ Haemorrhagic erosions (greater than $5 \mathrm{~mm}$ or small linear ulcers)

$3=\quad$ Many small linear ulcers (greater than $2 \mathrm{~mm}$ or a single linear)
$4=$
Multiple linear ulcers of marked size

\section{ULCER INDEX}

Number of rats xnumber of grades

Total number of rats in the group 


\section{ULCER INCIDENCE (\%)}

Divide number of rats with ulcer $\mathbf{x} 100$

$\underline{\text { total number of rats }}$

\section{Results}

\section{Histogram Representation of Mean Ulcer Score in the Different Experimental Groups}

The mean ulcer score for the control group was $8.5 \pm 0.5 \mathrm{mMol} / \mathrm{L} /$ hr. a significant $(\mathrm{P}<0.01)$ score of $14.75 \pm 0.48$ was recorded from animals fed with low dose of extract. A peak score of $20.5 \pm 0.96 \mathrm{mMol} / \mathrm{L} / \mathrm{hr}$ was obtained from animals fed with high dose of extract. This increase is statistically significant $(\mathrm{P}<0.001)$ compared to the control group.

\section{Discussion AND Conclusion}

\section{Discussion}

The results obtained showed a $60 \%$ increase in the number of ulcers formed in the group of rats fed with high dose of the extract compared to the control, and about $40 \%$ increase in number of ulcers formed in the rats fed with low dose of extract compared to the control. The mechanism by which Dennettiatripetala may have through Histaminergic pathway stimulated gastric acid secretion [1] and eroded the mucus guard of the stomach. This may have been aided by some pro-histamine ingredient in the extract eg nicotinic acid. It follows that Dennettiatripetala crude extract is a potent dose dependent trigger of gastric mucosa ulceration, hence should not be administered to peptic ulcer patients and those who are susceptible to gastric ulcer to prevent gastric ulceration. If however the medicinal benefit outweighs the risk, it could be administered with meal and in moderate dosage to reduce the risk.

\section{Conclusion}

Dennettiatripetala is a poor cytoprotective agent in rats because it attacks the gastric mucosa. The mechanism by which it does it was not part of this work and may therefore be investigated in another experiment. Further research is recommended in human to determine if the effect is similar.

\section{Reference}

1. Bright E, Mfem C, Ugumanim A, Ukpong M (2017) The effect of ethanol extract of Dennettia tripetala (Pepper fruit) on gastric acid secretion in wister rats. Research \& Reviews: Journal of Medical and Health Sciences.

2. Sylvia OI (2015) A review of the uses and medicinal properties of Dennettiatripetala (Pepper fruit). Med Sci 3(4): 104-111.

3. Okwu DE, Morah FN (2005) Mineral and nutritive value of Dennettiatripetala fruits. Glob J Pure Appl Sci 7: 455-459.

4. Ikpi DE, Nku CO (2008) Effect of ethanolic extract of Dennettiatripetala fruit on haematological parameters in albino Wister rats. Nigeria Journal of Physiological Sciences 23(1-2): 13-17.

5. IbuJO, Obuoforibo AA, Ezeamusie IC, Ngeribara CO (1986) Cytoprotective effect of pirenzepine and palm wine on rats gastric mucosa. Scand J Gastroenterol 124: 209-221.

6. Ohara SA (2016) Chronological Increase in Gastric Acid Secretion from 1995 to 2014 in Young Japanese Healthy Volunteers under the Age of 40 Years Old. The Tohoku Journal of Experimental Medicine 239(3): 237241. 